\title{
A study on the effect of manager's leadership style to create innovation among employees
}

\author{
Morteza Amani Ashlubolagh ${ }^{\mathrm{a}}$, Mohsen Ameri Shahrabi ${ }^{\mathrm{b}^{*}}$, Javad Eftekhari ${ }^{\mathrm{c}}$, Alieh Kazemi Ashlaghi ${ }^{\mathrm{d}}$, \\ Saeid Safdari ${ }^{\mathrm{d}}$ and Saber Abdolmaleki ${ }^{\mathrm{e}}$
}

${ }^{a} P h D$ Candidate in Educational Administration, Kharazmi University, Tehran, Iran

${ }^{b}$ Faculty member, Department of English and Management, Naragh Branch, Islamic Azad University, Naragh, Iran

${ }^{c}$ Manager of Credit \& Equipping the Sources, Mehr Bank, Tehran, Iran

${ }^{d}$ Department of Management, Naragh Branch, Islamic Azad University, Naragh, Iran

${ }^{e} M A$ in Educational Research, Tehran University, Tehran, Iran

\section{CH R O N I C L E}

\section{Article history:}

Received May 12, 2013

Received in revised format

25 June 2013

Accepted 5 August 2013

Available online

August 52013

Keywords:

Leadership

Innovation

Iran Khodro

\section{Introduction}

Innovation plays an important role on any organization and a firm with low level of creativity and innovation may face serious problems in handling issues. There are various studies on learning the effects of leadership style on having more innovation in organization (Abdolmaleki et al., 2013). In fact, there is no doubt that different leadership styles have various impacts on firms' components such as innovation, organizational change, etc. (Ehigie \& Akpan, 2004). Sehhat et al. (2012) studied the relationship between informal communications with leadership style in Iran and reported that there was a positive and meaningful relationship between leadership style and informal relationships. Moghaddas Pour et al. (2012) studied the relationship between relationship-oriented leadership style

*Corresponding author.

E-mail address: mohsenamerishah@yahoo.com (M. Ameri Shahrabi)

C) 2013 Growing Science Ltd. All rights reserved.

doi: $10.5267 / \mathrm{j} . \mathrm{ms} 1.2013 .08 .009$ 
and solution-oriented strategy as well as between leadership style and conflict management. They reported that there was only a meaningful relationship between relationship-oriented leadership with solution-based conflict management. In fact, the survey confirmed that when there was a conflict, management could handle the problem using his/her relationship and find appropriate solution to resolve any possible conflict.

Morshedian Rafiee and Mohammadi (2012) studied the relationship between leadership style and self-esteem by considering four groups of leadership style including autocratic-charity, autocraticexploitation, management consulting and participative and their effects on self-esteem. The results of the survey indicated that there was a positive and strong relationship between participative leadership management style and self-esteem. The results also indicated that there was a strong relationship between educational background and self-esteem.

Derakhshandeh and Gholami (2012) investigated the relationship between leadership style and perceived organizational effectiveness by directors and managers in some firms and confirmed that there was a meaningful and positive relationship between leadership style and perceived organizational effectiveness. Malmir et al. (2013) reviewed recent advances on leadership style and various perspectives of organizational cultures completed during the past few years.

Shalley and Gilson (2004) reviewed contextual factors that could either foster or hinder employee creativity at the individual, job, group, and organizational level. They studied the impact of leadership and the implementation of different human resource practices for developing a work context that was supportive of creativity. They discussed practical implications for managers, proposed areas that needed further research attention, and highlight possible new directions for future research.

Oldham and Cummings (1996) studied the independent and contributions of employees' creativityrelevant personal characteristics and three specifications of the organizational context-job complexity, supportive supervision, and controlling supervision-to three indicators of employees' creative performance; patent disclosures written, contributions to a firm suggestion program, and supervisory ratings of creativity. According to Mumford (2003) and Mumford and Licuanan (2004), the need for innovation in organizations has resulted in a new concentration on the role of leaders in shaping the nature and success of creative efforts. De Jong and Den Hartog (2007) provided an inventory of leader behaviors likely to enhance employees' innovative behavior, including idea generation and application behavior. According to Anderson et al. (2004) facilitators of innovation at the individual, group, and organizational levels were not well identified and suggested more discussion on this issue.

\section{The proposed study}

In this paper, we perform an empirical investigation to find out the effect of leadership style among middle level managers of Iran Khodro to promote innovation among regular workers. The proposed study of this paper considers the following questions,

1. What is the status of middle level managers' behavior in Iran Khodro?

2. What are the priorities of middle level managers' behavior in Iran Khodro?

3. What is the status of innovation in Iran Khodro?

4. Do middle level managers' behaviors influence regular employee's innovation?

The proposed study of this paper designs a questionnaire and distributes it among a sample of 278 regular employee and 61 middle level managers of this firm. All questions were designed in Likert scale from one to five and distributed among the sample size. Cronbach alphas for leadership style and innovation have been calculated as 0.77 and 0.92 , respectively. The proposed study of this paper 
uses factor analysis to examine different hypotheses of this survey. Table 1 demonstrates some of the basic statistics.

Table 1

Basic statistics associated with factor analysis

\begin{tabular}{ccccc}
\hline Item & Criterion & Condition & Leadership & Innovation \\
\hline 1 & Chi-Square & - & 217.41 & 478.35 \\
2 & df & - & 189 & 259 \\
3 & Chi-square/df & $<2$ & 1.15 & 1.84 \\
4 & RMSEA & $<0.05$ & 0.03 & 0.039 \\
5 & CFI & $>0.9$ & 0.94 & 0.92 \\
6 & GFI & $>0.9$ & 0.92 & 0.94 \\
7 & AFGI & $>0.9$ & 0.9 & 0.9 \\
8 & PGFI & $>0.9$ & 0.78 & 0.77 \\
\hline
\end{tabular}

The results of Table indicate that all statistical observations are within acceptable limits for both leadership and innovation components. Therefore, we can rely on the results of the survey. Table 2 and Table 3 show mean and standard deviation for two groups of survey including leadership and innovation.

Table 2

Mean and standard deviation for innovation and leadership

\begin{tabular}{llccc}
\hline Item & & Frequency & Mean & Standard deviation \\
\hline 1 & Leadership style & 61 & 3.27 & 0.318 \\
2 & Innovation & 278 & 2.16 & 0.201 \\
\hline
\end{tabular}

\section{The results}

In this section, we examine different hypotheses of the survey.

\subsection{The first hypothesis: Leadership status}

The first hypothesis of this survey investigates the status of different components of leadership on employees. Table 3 demonstrates the summary of our findings,

Table 3

The summary of testing the first hypothesis of the survey

\begin{tabular}{llccccc}
\hline & Mean & Standard & t-value & df & Sig. \\
\hline 1 & Innovative role-modeling & 2.34 & 0.319 & 5.21 & 60 & 0.01 \\
2 & Intellectual stimulation & 2.81 & 0.318 & 4.78 & 60 & 0.01 \\
3 & Stimulating knowledge & 2.87 & 0.218 & 3.52 & 60 & 0.01 \\
4 & Providing vision & 2.58 & 0.318 & 4.62 & 60 & 0.01 \\
5 & Consulting & 2.71 & 0.214 & 3.57 & 60 & 0.01 \\
6 & Delegating & 1.91 & 0.189 & 5.69 & 60 & 0.01 \\
7 & Support for innovation & 2.78 & 0.358 & 4.12 & 60 & 0.01 \\
8 & Organizing feedback & 2.46 & 0.234 & 3.72 & 60 & 0.01 \\
9 & Recognition & 2.91 & 0.359 & 2.59 & 60 & 0.01 \\
10 & Rewards & 2.49 & 0.318 & 4.32 & 60 & 0.01 \\
11 & Providing resources & 2.61 & 0.314 & 3.71 & 60 & 0.01 \\
12 & Monitoring & 2.74 & 0.211 & 3.55 & 60 & 0.01 \\
13 & Task assignment & 2.82 & 0.445 & 3.22 & 60 & 0.01 \\
14 & Leadership behavior & 2.51 & 0.319 & 3.54 & 60 & 0.01 \\
\hline
\end{tabular}


As we can observe from the results of Table 3, all components of leadership behavior are statistically significant $(\alpha=5 \%)$ leading us to conclude that leadership behavior and style plays essential role on innovation and the first hypothesis of the survey has been confirmed.

\subsection{Ranking leadership effects using Freedman test}

The second hypothesis of this survey uses Freedman test to rank different components of leadership style. Table 4 shows details of our findings,

\section{Table 4}

The results of Freedman test

\begin{tabular}{clcc}
\hline & & Mean & Rank \\
\hline 1 & Innovative role-modeling & 3.27 & 3 \\
2 & Intellectual stimulation & 3.34 & 2 \\
3 & Stimulating knowledge diffusion & 3.81 & 1 \\
4 & Providing vision & 2.92 & 4 \\
5 & Consulting & 2.87 & 5 \\
6 & Delegating & 2.58 & 7 \\
7 & Support for innovation & 2.16 & 8 \\
8 & Organizing feedback & 2.71 & 6 \\
9 & Recognition & 1.91 & 9 \\
10 & Rewards & 1.89 & 10 \\
11 & Providing resources & 1.69 & 13 \\
12 & Monitoring & 1.76 & 11 \\
13 & Task assignment & 1.72 & 12 \\
\hline
\end{tabular}

According to the results of Table 4, stimulating knowledge diffusion is number one priority followed by intellectual stimulation and innovative role-modeling.

\subsection{The effect of innovation}

The third hypothesis of this survey is associated with the effect of innovation in Iran Khodro. Table 5 demonstrates the results of t-student on various components of innovation.

Table 5

The result of testing the effects of innovation components

\begin{tabular}{llccccc}
\hline & & Mean & Standard & t-student & df & Sig. \\
\hline 1 & Environmental & 2.31 & 0.319 & 5.36 & 277 & 0.01 \\
2 & Leadership innovation & 2.44 & 0.308 & 3.45 & 277 & 0.01 \\
3 & Individual innovation & 2.51 & 0.218 & 4.17 & 277 & 0.01 \\
4 & Environment-feedback & 2.39 & 0.318 & 4.89 & 277 & 0.01 \\
5 & Individual-feedback & 2.52 & 0.214 & 3.69 & 277 & 0.01 \\
6 & Innovation & 2.31 & 0.319 & 2.98 & 277 & 0.01 \\
\hline
\end{tabular}

According to the results of Table 5, all components of innovation are statistically meaningful wen the level of significance is five percent.

\subsection{Ranking innovation effects using Freedman test}

The fourth hypothesis of this survey uses Freedman test to rank different components of innovation. Table 6 shows details of our findings, 
Table 6

The results of Freedman test

\begin{tabular}{clcc}
\hline & & Mean & Rank \\
\hline 1 & Environmental innovation & 3.01 & 4 \\
2 & Leadership innovation & 4.06 & 1 \\
3 & Individual innovation & 3.58 & 2 \\
4 & Environment-feedback & 3.10 & 3 \\
5 & Individual-feedback & 2.01 & 5 \\
\hline
\end{tabular}

As we can observe from the results of Table 6, leadership innovation is number one priority followed by individual innovation and environment-feedback.

\subsection{The effect of leadership on innovation}

The last hypothesis of this survey studies whether different components of leadership influences innovation or not. To test this hypothesis, we use linear regression technique and Table 7 shows the results of our investigation.

Table 7

The summary of regression analysis

\begin{tabular}{cccc}
\hline Pearson correlation & Multi-purpose coefficient & Adj. coefficient & Standard Error \\
\hline 0.386 & 0.148 & 0.141 & 2.79 \\
\hline
\end{tabular}

The results of Table 7 show that there is a positive relationship between leadership behavior and innovation in our case study. This leads us to conclude that the fifth hypothesis of this survey is confirmed. Table 8 shows the results of ANOVA test on our regression analysis.

Table 8

The summary of ANNOVA test

\begin{tabular}{lccccc}
\hline Source of changes & Sum of changes & df & Mean of changes & F & Sig. \\
\hline Regression & 287.18 & 13 & 35.89 & 30.93 & 0.01 \\
Error & 456.11 & 261 & 1.16 & & \\
\hline Total & 743.29 & 277 & & & \\
\hline
\end{tabular}

The result of Table 8 clearly validates the linear relationship between independent variables and dependent variable, innovation. Finally, Table 9 summarizes the results of regression analysis.

Table 9

The summary of regression analysis

\begin{tabular}{clccccc}
\hline & & $\begin{array}{c}\text { Non-standard } \\
\text { coefficient }\end{array}$ & $\begin{array}{c}\text { Standard } \\
\text { Error }\end{array}$ & $\begin{array}{c}\text { Standard } \\
\text { coefficient }\end{array}$ & t-value & Sig. \\
\hline 1 & Innovative role-modeling & 18.79 & 0.789 & - & 23.81 & 0.05 \\
2 & Intellectual stimulation & 11.44 & 0.312 & 0.281 & 36.66 & 0.05 \\
3 & Stimulating knowledge & 10.23 & 0.561 & 0.242 & 18.23 & 0.05 \\
4 & Providing vision & 9.29 & 0.632 & 0.225 & 14.69 & 0.05 \\
5 & Consulting & 8.11 & 0.242 & 0.198 & 33.15 & 0.05 \\
6 & Delegating & 7.34 & 0.654 & 0.167 & 11.22 & 0.05 \\
7 & Support for innovation & 6.43 & 0.451 & 0.143 & 14.25 & 0.05 \\
8 & Organizing feedback & 5.89 & 0.347 & 0.127 & 16.97 & 0.05 \\
9 & Recognition & 4.56 & 0.378 & 0.115 & 12.06 & 0.05 \\
10 & Rewards & 3.21 & 0.267 & 0.097 & 12.02 & 0.05 \\
11 & Providing resources & 3.01 & 0.314 & 0.089 & 10.54 & 0.05 \\
12 & Monitoring & 3.14 & 0.214 & 0.078 & 8.02 & 0.05 \\
13 & Task assignment & 2.98 & 0.236 & 0.067 & 5.12 & 0.05 \\
\hline
\end{tabular}


The results of Table 9 specify that Innovative role-modeling with standard coefficient of 0.789 has the highest positive impact followed by providing vision with standard coefficient of 0.632 . In summary, all leadership components maintain positive influence on innovation.

\section{Conclusion}

In this paper, we have investigated the effect of leadership style among middle level managers of Iran Khodro to promote innovation among regular workers. The proposed study designed a questionnaire and distributed it among middle level managers of this auto-maker. The results of t-student values indicate that all leadership behavior of middle level have positive influence on innovation and Freedman test implied that stimulating knowledge diffusion was number one priority followed by intellectual stimulation and innovative role-modeling. We have also performed multi-regression analysis and the results have indicated that there were some positive relationship between leadership components and innovation.

\section{References}

Abdolmaleki, J., Amani Ashloublagh, M., Ameri Shahrabi, M., Kazemi Ashlaghi, A., \& Safdari, S. (2013). A study on effects of leadership style on innovation: A case study from automaker industry. Management Science Letters, 3(7), 1977-1982.

Anderson, N., De Dreu, C. K., \& Nijstad, B. A. (2004). The routinization of innovation research: A constructively critical review of the state-of-the-science. Journal of organizational Behavior, 25(2), 147-173.

De Jong, J. P., \& Den Hartog, D. N. (2007). How leaders influence employees' innovative behaviour. European Journal of Innovation Management, 10(1), 41-64.

Derakhshandeh, A \& Gholami, R. (2012). A relationship between leadership style and perceived organizational effectiveness by directors and managers in organizations. Management Science Letters, 2(3), 845-850.

Ehigie, B. O., \& Akpan, R. C. (2004). Roles of perceived leadership styles and rewards in the practice of total quality management. Leadership \& Organization Development Journal, 25(1), 24-40.

Malmir, M., Esfahani, M \& Emami, M. (2013). An investigation on leadership styles in different cultures. Management Science Letters, 3(5), 1491-1496.

Moghaddas Pour, S., Bakhshizadeh, A \& Barati, E. (2012). An empirical study to measure the relationship between management style and conflict management. Management Science Letters, 2(6), 2249-2254.

Morshedian Rafiee, S., \& Mohammadi, M. (2012). Leadership styles and its relationship with subordinates \& quot; self-esteem. Management Science Letters, 2(7), 2457-2462.

Mumford, M. D. (2003). Where have we been, where are we going? Taking stock in creativity research. Creativity Research Journal, 15(2-3), 107-120.

Mumford, M. D., \& Licuanan, B. (2004). Leading for innovation: Conclusions, issues, and directions. The leadership quarterly, 15(1), 163-171.

Oldham, G. R., \& Cummings, A. (1996). Employee creativity: Personal and contextual factors at work. Academy of management journal, 39(3), 607-634.

Sehhat, S., Kenari, M \& Alipour, M. (2012). The effect of informal communication on the leadership styles in governmental organizations. Management Science Letters, 2(7), 2637-2642.

Shalley, C. E., \& Gilson, L. L. (2004). What leaders need to know: A review of social and contextual factors that can foster or hinder creativity. The Leadership Quarterly, 15(1), 33-53. 